\title{
Effects of an Inquiry-Focused, Content-Intensive Program on Pre-Kindergarten-9th Grade Teachers' Content Knowledge, Self-Efficacy, and Goals
}

\author{
Patricia Nugent, (Associate Professor, PhD) \\ Michelle Edgcomb Friday, (Tenured Lecturer, M.S.) \\ Wayne Evens, (Associate Professor, PhD) \\ KellyMcConnaughay, (Associate Dean, PhD) \\ Sherrie Morris, (Professor, PhD) \\ Kevin Finson, (Professor, PhD) \\ Robert Wolffe, (Professor, Ed.D.) \\ Heljä Antola Crowe, (Professor, PhD) \\ Bradley University, USA
}

Doi: 10.19044/esj.2017.v13n34p363 URL:http://dx.doi.org/10.19044/esj.2017.v13n34p363

\begin{abstract}
This study describes the effects of an inquiry-focused, contentintensive professional development program on Pre-kindergarten- $9^{\text {th }}$ grade teachers' science and mathematics knowledge, use of classroom based inquiry, improvement in their science teaching self-efficacy and other motivation constructs. This two-and-a-half-year program was designed to meet the needs of teachers in a local urban school district. The professional development in the form of a graduate program intentionally sought to emphasize science and mathematics content knowledge and inquiry teaching. Twenty experimental teacher-participants were involved in the program with twelve additional teachers as a control group. Data collection instruments used for this study included content testing, student test-scores, self-efficacy belief surveys, and behavioral scales. The results of the study indicated greater growth for program participants in the areas of science and mathematics content knowledge. The participants also showed greater increases in science teaching self-efficacy as compared to the teachers in the control group.
\end{abstract}

Keywords: Inquiry, program-evaluation, STEM, professional development, self-efficacy 


\section{Introduction:}

There is a widespread desire and effort to increase recruitment, retention and quality of teachers in science, technology, engineering and mathematics (STEM) education. The U.S. Department of Education and the National Science Foundation have both developed Mathematics-Science Partnership (MSP) programs. In response to these efforts, Bradley University created a Professional Master's Degree (PMA) program. To create this program, development, initial implementation and research was funded by a Department of Education MSP grant channeled through the State of Illinois Department of Education. As a result of this funding, the first cohort of area teachers completed Bradley University's program to improve STEM teaching in public schools. This article describes the planning, implementation, and evaluation of the program and its effects on teachers' knowledge, confidence, and abilities in inquiry-oriented STEM education. Twenty Pre-kindergarten-9th grade teachers, all members of the first cohort, completed the program successfully. The program was targeted to improve Pre-kindergarten-9th grade science and mathematics teaching in central Illinois.

\section{I.}

The PMA program in elementary STEM education was developed through a partnership between the university and the local school district. The school district is located in a metropolitan area (populationapproximately 115,000 city/379,000 Tri-county area), has four high schools, ten middle schools (some overlap with elementary), fourteen elementary schools, and enrolls over 13,300 students per year. It serves a large population of students from groups traditionally underrepresented in STEM disciplines, particularly African-Americans (57\% vs. $17 \%$ statewide average), and students from economically disadvantaged families (68\% vs. $50 \%$ statewide average) (Illinois School Report Card, 2017). The district suffers from higher chronic truancy rates, higher school dropout rates, and lower standardized test scores than statewide averages. Sixteen of the twenty-five schools in the district are on School Improvement Status, with three having been on this list since the inception of the No Child Left Behind Act of 2001. The district has dealt with budget deficits throughout the period of this program and has also experienced several changes in administration. These factors contribute additional challenges to those ordinarily faced by all teachers.

The program was administered by the university's Center for STEM Education. Both the center and the College of Education and Health Sciences have a strong ongoing relationship with the local school district. The Center for STEM Education was the result of a cooperative venture between the 
College of Liberal Arts and Sciences, the College of Engineering, and the College of Education and Health Sciences.

\section{Literature Review}

The PMA steering committee was guided by three needs assessments: two were local needs surveys administered in 2004 and 2006 assessing the STEM-related needs of K-12 educators in the school district. The third was a statewide survey of K-12 teachers in Illinois (Patton \& Schnite, 2005). All three surveys indicated that classroom teachers need science and mathematics materials and a more in-depth understanding of pedagogical content knowledge. Guided by these needs assessments, the steering committee reviewed best practices in the literature and in state and national mathematics and science standards. Of particular relevance for this process were guidelines for developing professional development for science and mathematics teachers (Loucks-Horsley, Love, Stiles, Mundry \& Hewson, 2003) and standards for teaching and learning (Zemelman, Daniels \& Hyde, 1993). From this review, five key elements were identified to guide program development:

1) contextual learning experiences are critical to engagement and retention of knowledge;

2) meta-cognitive activities increase integration of knowledge and awareness of both personal growth and areas needing improvement;

3) active participation in the learning process, from planning to assessment, enhances learning and empowers participants;

4) knowledge acquisition is supported through a crossdisciplinary approach, as it allows for increased complexity in neural networking; and

5) self-efficacy effects progress made by learners and teachers.

Although all key elements were recognized in planning the professional development, some key elements are more clearly identified as components in the program. For example, as stated in number one above, learning is enhanced when it is contextualized in the lives of the learner (Fosnot \& Perry, 2005). The university had, for three years, been operating a program in which Pre-kindergarten-12 ${ }^{\text {th }}$ grade teachers spent 150-200 hours working with scientists in active research labs. To optimize the learning potential and future classroom application of these experiences, the PMA program was designed to include extensive experiences with scientific processes, inquiry-based instruction, and the effective use of technologies. The program was designed to involve teachers in research experiences that also included events where they presented results. 
Inquiry-based teaching incorporates several key elements. Thus, inquiry-based teaching was the main focus for curriculum implementation in the PMA program. Inquiry-based teaching is a process of developing classroom activities that reflect the modes of investigation of practicing scientists (Jarrett, 1997, 1999). Training in inquiry curriculum development and action research lead to greater gains in teachers' comfort with and likelihood of teaching inquiry-based science compared with professional development programs that focus only on science content mastery (National Research Council, 1996, 2000, 2013). Benefits of inquiry learning for students include a better understanding of science and increased science literacy, critical thinking, and positive attitudes toward science (Haury, 1993). For these reasons, national standards in mathematics and science (American Association for the Advancement of Science, 1993; National Council of Teacher of Mathematics, 2000; National Research Council, 1996, 2000, 2013; Rutherford \& Ahlgren, 1990) and state content standards require integration of problem solving and inquiry into the curriculum, with several methods of inquiry instruction proposed (Jarrett, 1997, 1999; Edgcomb, Britner, McConnaughay, Wolffe, 2008).

The PMA program was also designed to assist teachers to develop and apply a better understanding of state and national mathematics and science standards, a need indicated by the 2004 and 2006 surveys. Student achievement improves when the content taught in classrooms aligns with standards and assessments (U.S. Department of Education, 1999). National science education standards delineate specific content areas essential for teaching and learning science that emphasize cross-disciplinary and realworld examples within science and technology; science in personal and social perspectives undertaken in making decisions on the environment, science, and society; and the history and nature of science (National Research Council, 1996, 2000, 2013). The National Council of Teachers of Mathematics (NCTM) provides similar standards in the domain of mathematics. The 2000, Principles and Standards, in place when the program was designed, documents six principles to lead mathematics teaching and learning. In addition, it provides five content specific standards and five process standards. Although standards provide guidance for content and methodologies for teaching content in science and mathematics, teachers must have the knowledge and skills to select the content and adapt curriculum and instructional methodologies to meet the needs, interests, and experiences of the students (Zemelman, et al., 1993).

The program was intentionally designed to be taught as a partnership of STEM and teacher education (curriculum, instructional design, teacher leadership) faculty. The curriculum and course development was guided by the five elements mentioned previously. Specifically, courses were designed 
with cross-disciplinary contextual learning experiences that involved active participation. Participants integrated knowledge of their personal growth while monitoring their own self-efficacy. All courses were taught using inquiry-based teaching in order to model effective use of the strategies. The program was developed so that each teacher participant would have the experience of conducting and reporting on scientific research by working with a practicing scientist in his or her laboratory for ten weeks in the second summer of the program, thus gaining a deeper understanding of scientific research processes. One example of this was teachers in the program working with robotics at National Aeronautics and Space Administration's (NASA) Goddard Space Flight Center.

To assist teachers in integrating the content knowledge and pedagogy learned in the program, a capstone experience was designed that required teachers to develop an inquiry-based unit of study. During the last semester of the program, teacher participants taught this inquiry-based unit in their classrooms while conducting an action research project. In preparation for this capstone experience, teachers were given the opportunity to teach one another through innovative lesson plans that could be used in the classroom. In addition, they had the opportunity to plan and deliver a professional development workshop to teachers outside the program cohort as a part of their final capstone experience. Two models guided the planning for this experience: Science: Parents, Activities, and Literature (Science PALS) program (Yore, Anderson \& Shymanski, 2005), and Math in the Middle Institute Partnership (Cabrera, Nora, \& Casteneda, 1993; Heaton \& Hartman, 2006). Both programs had educators serve as lead teachers to teach and train peers to implement STEM activities in their classrooms.

To assist in their meta-cognitive reflection and professional development, all program teachers were given an annual personal profile that detailed their progress as learners of STEM content and process skills and as inquiry-teaching practitioners in their classrooms. A section of these profiles compared each teacher's progress to that of other cohort members.

The program was implemented as a 33-hour Professional Masters of Arts (PMA) degree spanning two-and-a-half years with the following primary goals:

1. increase the Math, Science, Engineering and Technology content and process knowledge, and skills of the candidates enrolled in the program;

2. increase the candidate's feelings of self-efficacy related to mathematics and science; and

3. increase the candidate's understanding of what motivates them as adult learners. 
Figure 1 shows the timeline and course structure for the PMA degree program. The intent of the first summer was to immerse participants in the model of inquiry-based instruction and introduce them to the concepts of research and teacher leadership. During the first fall, participants took their first content-elective course ( 3 credits). These content-elective courses were inquiry-based and integrated lecture, discussions and labs. In addition, they focused on interdisciplinary science and math content. During the first spring, participants looked at methods and practice of analyzing and modifying inquiry-based curriculum content, pedagogy and assessment.

Figure 1: PMA Timeline and Course Structure

\begin{tabular}{|l|l|}
\hline Time Period & Courses Taken \\
\hline Summer 1 & $\begin{array}{l}\text { Science Through Inquiry (3 credits) } \\
\text { Math Through Inquiry (3 credits) } \\
\text { Directed Research in Science and Math (1 credit) } \\
\text { Introduction to Educational Leadership (1 credit) }\end{array}$ \\
\hline Fall 1 & Content-Elective Course (3 credits) \\
\hline Spring 1 & Curriculum Development \& Analysis (3 credits) \\
\hline Summer 2 & $\begin{array}{l}\text { Science Through Inquiry II (3 credits) } \\
\text { Research in Math and Science (2 credits) }\end{array}$ \\
\hline Fall 2 & Action Research Course (3 credits) \\
\hline Spring 2 & Content-Elective Course (3 credits) \\
\hline Summer 3 & $\begin{array}{l}\text { Nature of Inquiry and Innovation (3 credits) } \\
\text { Advanced Educational Leadership (2 credits) } \\
\text { STEM Education Project (1 credit) }\end{array}$ \\
\hline Fall 3 & STEM Education Project (1 credit) \\
\hline
\end{tabular}

During the second summer, the inquiry course expanded on techniques and concepts from the previous summer scientific topics. In the research course, participants were assigned to a research mentor and completed 150-200 hours in research immersion as described above. This summer experience was followed in the second fall with a course on designing and implementing action research. In the second spring, participants took their second content-elective course.

In the final summer, teacher participants completed six semester hours. In the first course, participants addressed issues related to inquiry across disciplines as well as historical and societal perspectives of innovation. They then took their second leadership course which allowed the participants to look at the challenges and practice in educational leadership. 
The last course, provided the participants an opportunity to address curriculum development as informed by their research immersion experience. This course was split with one hour in the summer, to plan for the capstone experience. The remaining two credit hours were completed in the fall, which allowed for the completion of the teacher participant's action research project.

In planning to assess each of the above-mentioned goals, the planning/evaluation team constructed a Logic Model for the PMA degree (see figure 2).

Figure 2: Bradley University's IMSP Elementary Math/Science Logic Model

Goal 1: Increase the Math, Science, Engineering and Technology content and process knowledge skills of the candidates enrolled in the program.

\begin{tabular}{|l|l|}
\hline Expected Outcome & $\begin{array}{l}\text { Cohort members will show statistically } \\
\text { significant gains in measures used for } \\
\text { evaluations. In addition, Math scores } \\
\text { will meet or exceed the 50th percentile. }\end{array}$ \\
\hline Evaluation & $\begin{array}{l}\text { Math Knowledge: LMT Elementary } \\
\text { numbers, ratios, and fractions, rational } \\
\text { numbers, middle school geometry and } \\
\text { algebra Kara } \\
\text { Science Knowledge: DTAMS: Earth } \\
\text { Science, Physical Science, Life Science }\end{array}$ \\
\hline
\end{tabular}

Goal 2: Increase the candidate's feeling of self-efficacy related to mathematics and science.

\begin{tabular}{|l|l|}
\hline Expected Outcome & $\begin{array}{l}\text { Cohort members will show statistically } \\
\text { significant gains in measures used for } \\
\text { evaluations. }\end{array}$ \\
\hline Evaluation & $\begin{array}{l}\text { Math Anxiety } \\
\text { Science Anxiety } \\
\text { STEBI-A }\end{array}$ \\
\hline
\end{tabular}

Goal 3: Increase the candidate's understanding of what motivates them as adult learners.

\begin{tabular}{|l|l|}
\hline Expected Outcome & $\begin{array}{l}\text { Cohort members discover what } \\
\text { motivates them as adult learners. }\end{array}$ \\
\hline Evaluation & $\begin{array}{l}\text { GAS } \\
\text { BI Indicators }\end{array}$ \\
\hline
\end{tabular}




\section{Methods \\ Participants}

The cohort was comprised of twenty program completers who were Pre-kindergarten $-9^{\text {th }}$ grade teachers. These participants had completed two to nineteen years' teaching experience at their current assignment. All teacherparticipants were considered highly qualified, in that they held current Illinois teaching certificates and specific endorsements for their teaching assignments. The cohort included four teachers who taught students with special needs, six who taught early childhood, and eight who taught middle school mathematics or science. Sixteen were white females, two were white males, and two were African-American females. There were twelve control group teachers, all from the same local school district and matched to program teachers in terms of degrees earned, years of teaching experience, current teaching assignments, gender, and number of mathematics and science courses completed.

Instruments

Assessment instruments include those for program participant content mastery (both mathematics and science), self-efficacy measures and motivation factors.

Goal 1: Teacher Content and Skills Mastery in Mathematics and Science.

Learning Mathematics for Teaching (LMT) from University of Michigan School of Education (2008). Five of the instrument's scales were used. The scales were: elementary number concepts, ratios and fractions, rational numbers, middle school geometry, and middle school algebra. For the elementary number concepts scale, instrument developers reported using Item Response Theory (IRT) to establish overall and subscale reliabilities, which assumes normal distribution of measured traits (Hill, et al., 2008). Instrument developers reported an overall reliability $r=0.80$. As an additional check, subscale reliabilities using Cronbach's alpha were checked and reliabilities very similar to those reported by the instrument's developers were obtained. As they have established validity with large samples, reliabilities of 0.80 or larger allowed use with small samples such as ours.

Diagnostic Teacher Assessments in Mathematics and Science (DTAMS) from University of Louisville (2012). The Diagnostic Teacher Assessments in Mathematics and Science (DTAMS) was used to measure science content knowledge. The earth science, physical science, and life science scales of the instrument were used. The instrument's developers used Cronbach's alpha to determine subscale reliabilities: Earth/space science scale V 1.2, alpha $=0.754$; life science scale V 3.2, alpha $=0.841$; physical science scale V 3.2, alpha $=0.873$. (Tretter, et al., 2005). The instrument also 
provided assessment of processes in mathematics and science, for example, teachers identify student misconceptions or how material is processed.

Goal 2: Self-Efficacy Assessments.

Science Teaching Efficacy Belief Instrument (STEBI-A). The Science Teaching Efficacy Belief Instrument (STEBI) (Enochs \& Riggs, 1990) was designed to assess teachers' science teaching efficacy beliefs and was based upon theoretical constructs described by Bandura (1977). The STEBI (form A for inservice teachers) consists of twenty-five statements that are divided to provide two subscores: Personal Science Teaching Efficacy Beliefs Scale (PSTE) (thirteen items), and the Science Teaching Outcome Expectancy Scale (STOE) (twelve items). PSTE refers to a teacher's belief in his/her abilities and skills in effectively teaching a subject such as science, while STOE refers to a teacher's belief that he/she can be successful helping students learn considering factors beyond the teacher's control. Typically, PSTE is more readily influenced and more susceptible to change than is STOE. Teachers who are highly self-efficacious tend to be more open to utilizing inquiry types of instruction, attempting new things, and are less dogmatic in adherence to didactic techniques. Sub-score statements are randomly embedded within the instrument and are divided between PSTE and STOE subscales. Half of the items within each subscale are phrased positively while the remainder of the items are reversely phrased (i.e. negatively phrased). Each statement has a five-point Likert scale from which respondents select their answers, with $5=$ strongly agree, $4=$ agree, $3=$ uncertain, 2 = disagree, and 1 = strongly disagree. The scoring format is constructed so that positively phrased statements are awarded with numeric scores matching the respondent's choice (e.g. $5=5$ points), whereas the scores awarded for negatively phrased statements are the opposite (e.g. $5=1$ point). The range of PSTE scores possible is 13-65 while that of STOE scores is 12-60. The two sub-scores are not additive, meaning the user cannot add the PSTE and STOE sub-scores together to derive an "overall" STEBI score. The instrument's developers used factor analysis to determine instrument reliability, and reported reliability coefficients of 0.90 and 0.79 for the PSTE and STOE subscales, respectively.

Goal 3: Motivation Assessments.

Behavioral Intentions (BI) Scales. The BI asks participants to rate the importance and likelihood of occurrence of costs and benefits for accomplishing a particular behavior or behavioral sequence, in this case completion of the PMA program and to implement more effective pedagogy. The behavioral intentions scaling (Ajzen \& Fishbein, 1980) is a technique that has been used in many settings to predict behavior. For this assessment, teachers were asked to identify five to ten behaviors they needed to engage in to complete the program and change their pedagogy. They were then 
asked to identify one to ten payoffs they see for doing this behavior, along with their assessment of how likely (on a 1 to 10 scale - which converts to decimal values) they were to receive the pay off, and they assessed the value of each payoff to them. In addition, they were asked to identify what norms of values (personal and social) they see as relevant to each behavior. On a ten-point scale they assessed the salience of each norm and their motivation to comply with the norm. All of this was fed into an equation that predicted behavior. The beta weights in the equation were assigned by asking candidates to identify whether they tend to respond to payoffs or norms when making decisions, and to discuss how they had made similar decisions in the past. Each year they were asked to report whether and how much they were engaged in the identified behaviors. Participants also rate specified norms on relevance and their motivation to comply. Cost benefit values, motivational values, and a total BI score were then computed. Scores for each section can range from 0 to 5 , and because beta weights are used the BI score can range from 0 to 5 . The BI approach rests on predictive validity. Instrument developers report correlations in the 0.95 range between BI score and actual behaviors (Ajzen \& Fishbein, 1980). The underlying assumption made by the instrument developers is that people tend to do what they say they plan to do (Ajzen \& Fishbein, 1980). As Ajzen (1985) notes, intentions tend to weaken over time. This measure had no comparison group because it was specific to behavior in the program.

Goal Attainment Scaling (GAS). The Goal Attainment Scaling (GAS) (Kiresuk, Smith, \& Cardillo, 1994) asks participants to state their goals for completing a behavior sequence. It assesses teachers' goals pertinent to joining the degree program and their progress toward their goals as they advance toward their degree. Each teacher was asked to identify five to ten goals they had for joining the program. They rated the importance of each goal on a ten point scale. They identified specific behavioral indicators that measured how well they progressed toward the goal. In the GAS scale -2 indicates much less than the expected outcome; -1 indicates less than expected; 0 indicates most likely expected outcome; +1 indicates more than expected; and +2 indicates much more than expected. All goals and outcomes were specified in behavioral terms. Each scale then defines five possible outcomes from total failure $=1$ through met beyond all expectations $=5$ (Kiresuk, et al., 1994). Teacher-participants in the program and control group teachers' initial goals were analyzed and the perceptions of their progress over the years was tracked. Since the teachers in the control group were not completing a degree program, they were asked to respond with regard to professional development they anticipated over the next few years.

GAS has shown excellent psychometric properties in clinical and staff settings with change. The advantage with this instrument was that the 
candidates set their own goals. This allowed evaluators to assess each participant's progress toward their goals (Loucks-Horsley, Love, Stiles, Mundry \& Hewson, 2003).

Data Collection

Teacher-participants in the program and control group teachers were pretested with the LMT and DTAMS prior to the beginning of program coursework, summer 2008, and were then tested at one-year intervals, including one year after completion of the program. The STEBI-A, BI Scales and $G A S$ assessments were added during 2010 testing. As mentioned above, the BI Scales were not administered to the control group, as the instrument was specific to completing the program. All teachers completed all other instruments. This assessment allowed tracking of the progress of each participant, tracking the progress of the teachers as a whole, and comparison of the program teachers to the control group teachers.

\section{Data Analysis}

The program evaluation did not a contain a randomly generated control and experimental group, as the experimental group was defined as those teacher-participants enrolled in the PMA program. The initial plan was to recruit a control participant matched to each candidate; however, it was only possible to recruit twelve participants for the control group. Data from all measures were analyzed yearly, and summaries were provided to program management, the steering committee, and on some occasions to the school district administration. The analyses were both formative and summative. We used paired t-tests to compare participant data at different time points, and unpaired t-tests to compare program teachers to control group teachers.

Results

Goal 1: Teacher Content Mastery

Table 1 shows the average pre- and post-test scores for the program teachers on tests of mathematics and science content over the two-and-a-half years of the program (post-test taken one year after finishing the program). The program teachers showed significant gains in all areas of mathematics and science tested. In contrast, the teachers in the control group showed no significant change in any area of mathematics or sciencce. 


\begin{tabular}{|l|l|l|l|}
\hline $\begin{array}{l}\text { Table 1. Gains in Mathematics \& Science Content } \\
\text { Knowledge--Program Teachers } \\
\text { (Differences and significance based on paired } t \text {-tests, } \mathrm{n}=20)\end{array}$ & Pretest & Post Test & Difference \\
\hline & 9.38 & 11.14 & $1.76^{* * *}$ \\
\hline Elementary numbers & 12.42 & 15.21 & $2.79 * *$ \\
\hline Ratios and fractions & 10.14 & 13.78 & $3.64 * * *$ \\
\hline Rational numbers & 10.10 & 12.25 & $2.15^{*}$ \\
\hline Middle school geometry & 6.00 & 8.85 & $2.85 *$ \\
\hline Middle school algebra & & & \\
\hline & 15 & 20 & $5 * * *$ \\
\hline Earth Science & 17 & 24 & $7 * * *$ \\
\hline Life Science & 12 & 16 & $4 * *$ \\
\hline Physical Science & & & \\
\hline & & & \\
\hline
\end{tabular}

The science content test also provided scores for pedagogical content knowledge. These scores assess how effectively teachers identify student misconceptions or misunderstandings, and whether they are able to identify appropriate teaching methods for dealing with these misconceptions. The program teachers' scores showed a significant increase in earth science and life science pedagogical content knowledge ( $\mathrm{p}<.0001)$, and the control group teachers' scores showed a smaller, yet significant $(p<.05)$, increase in life science pedagogical content knowledge.

Goal 2: Self-Efficacy Assessments

\section{STEBI-A.}

The STEBI-A measures teachers' beliefs that science can be taught (Outcome Expectancy) and their belief that they, personally, can effectively teach science (Personal Science Teaching Efficacy). We administered the STEBI-A to both groups of teachers during the program (second year scores) and after the cohort had graduated (third year scores). Because our cohort had graduated and some had moved away or were otherwise unavailable, we have complete pre-post scores for fifteen of the twenty program teachers. 


\begin{tabular}{|c|c|c|c|c|}
\hline & \multicolumn{2}{|c|}{ Outcome Expectancy } & \multicolumn{2}{|c|}{$\begin{array}{l}\text { Personal Science } \\
\text { Teaching Efficacy }\end{array}$} \\
\hline & $2^{\text {nd }}$ Year & $3^{\text {rd }}$ Year & $2^{\text {nd }}$ Year & $3^{\text {rd }}$ Year \\
\hline $\begin{array}{l}\text { Program } \\
(\mathrm{n}=15)\end{array} \quad$ Teachers & 29.53 & $43.20 *$ & 36.20 & $44.47 *$ \\
\hline $\begin{array}{l}\text { Control Teachers } \\
(\mathrm{n}=11)\end{array}$ & 43.73 & 44.64 & 44.64 & $40.82 *$ \\
\hline
\end{tabular}

$* \mathrm{p}<.05, * *<.001, * * * \mathrm{p}<.0001$.

The program teachers showed significant increases in both outcome expectancy $(\mathrm{t}=-6.820, \mathrm{df}=14, \mathrm{p}=.0001)$ and their personal science teaching self-efficacy $(\mathrm{t}=-7.147, \mathrm{df}=14, \mathrm{p}=.0001)$. The control group teachers showed no significant change in outcome expectancy $(\mathrm{t}=-1.035$, df $=10, p=.325)$. They did, however, show a significant decrease in personal science teaching self-efficacy $(\mathrm{t}=-3.479, \mathrm{df}=10, \mathrm{p}=.006)$. There were no significant differences between the program teachers and control group teachers.

Goal 3: Motivation Assessments

Behavioral Intentions Scale. Teachers were asked to assess their likelihood of implementing and using inquiry-oriented instructional strategies in their classrooms. In an effort to determine their motivations for doing so, each teacher (in both the program and control groups) was asked to complete the Behavioral Intentions (BI) instrument. The BI was used to determine whether teachers would pursue the implementation and use of inquiry instruction (compliance) due to that action being an accepted norm, and/or because they saw that the benefits of doing so outweighed the costs associated with doing it. Analyses using t-test procedures were then applied to the data. During each year, program teachers expressed a stronger motivation to implement inquiry strategies and approaches than did teachers in the control group, although the motivation to do so appeared to decline across the four years of the program. Teachers in the program expressed that adhering more closely to the expected norm was more important to them than were cost/benefit issues for years one and three $\left(t_{1}=-2.366, p \leq 0.29 ; t_{3}\right.$ $=-4.099, \mathrm{p}<0.001$ ), and that the differences in motivation between norminduced reasons and cost/benefit-induced reasons significantly favored norm-induced reasons each year of the program $\left(\mathrm{t}_{1}=-3.362, \mathrm{p}<0.003 ; \mathrm{t}_{2}=-\right.$ $\left.4.84, \mathrm{p}<0.000 ; \mathrm{t}_{3}=-3.643, \mathrm{p}<0.002 ; \mathrm{t}_{4}=-3.837, \mathrm{p}<0.002\right)$. The control 
teachers showed no significant differences in any of the areas measured by the Behavioral Intentions Scale.

Goal Attainment Scaling (GAS). In the first year of the program teachers stated their goals for this program and control teachers for professional development they planned; they then ranked each goal's importance on a 10-point scale. The most frequent and most highly important goals for the program teachers had to do with becoming a better teacher, specifically in mathematics and science. The second most frequently stated and highly rated goal had to do with increasing their content knowledge. Instrumental goals were stated less frequently and ranked as less important. However, control teachers stated more instrumental goals like increasing their pay, gaining a master's degree, and gaining specific skills in technology or evaluation techniques. On the final survey, all program teachers indicated that they had achieved or exceeded their expectations for their goals. The control teachers indicated much less goal progress.

\section{Conclusion:}

Teachers face increasing challenges every year, closely connected to the global realities of heightened communication needs, economies based on knowledge shared through multiple disciplines and perspectives, and complex cultural and professional demands (Hargreaves \& Shirley, 2012; Taylor \& Fratto, 2012). To prepare students for their own future in this challenging environment, teachers need a strong foundation in the STEM content and processes they teach, and the confidence that they themselves can teach effectively. Increasing participants' content and confidence was clearly met. Program teachers demonstrated significant increases in knowledge in all science and mathematics areas tested, while with one minor exception, control group teachers showed no increased knowledge. Although this study focused on a small sample size, given that increasing teacher content knowledge was one of the program's goals, this was an extremely encouraging result. Further studies, with greater sample sizes would need to be conducted to validate these findings.

Teachers' attitudes are an important factor in being able to demonstrate their competence (Artzt, Armour-Thomas, \& Curcio, 2008). In this study our program participants showed increases in both areas (Outcome Expectancy and Personal Science Teaching Efficacy) of self-efficacy assessed by the STEBI-A measure. Although we only had data from $75 \%$ of the program completers, it is important to note that teachers who believe that it is possible to have an effect on students, and who believe that they personally are competent teachers, will be more successful in teaching STEM content and processes. Meta-analysis of teacher induction and mentoring programs (Ingersoll, R.M., \& Strong, M., 2011) shows that 
consistent professional development has a positive impact on teachers especially in higher satisfaction in the job, commitment and retention. Goals and intentions are also important in teaching outcomes; in these areas, as well, program teachers benefited from the program, expressing higher intentions to implement the best teaching strategies and to continue to improve their teaching skills. Their strong science teaching self-efficacy and high levels of motivation, combined with the STEM content learned in the program, should well equip our program graduates to prepare their students.

As stated above, our programs goals were to:

1. increase the Math, Science, Engineering and Technology content and process knowledge, and skills of the candidates enrolled in the program;

2. increase the candidate's feelings of self-efficacy related to mathematics and science; and

3. increase the candidate's understanding of what motivates them as adult learners.

In this study these elements were accomplished through a graduate level program of study. The intentionality, the immersion into inquiry in integrative ways supported the beneficial results of teacher success related to the goals set for the program.

One other powerful outcome of the program was the establishment of a cohort that grew through the program together. The establishment of the cohort of program teachers created a community of practice (Wenger, McDermott \& Snyder, 2002; Lave \& Wenger, 1991) that exhibited a culture of supportive interactions, encouragement, and empowerment (Siitonen \& Robinson, 1998).

Due to the success of the graduate program and the accomplishments of the participants, we encourage further implementation of cohorts dedicated to the completion of an intentional STEM Master's degree program. Quantitative data, although limited in sample size supported the power of an inquiry-based program to increase participants' content understanding. These increases in content understanding paralleled increases in teaching self-efficacy. This intentional and consistent professional development format powerfully supported the birth of courage for an increased role in teacher leadership.

\section{References:}

1. Ajzen, I. (1985). From intentions to actions: A theory of planned behavior. In J. Kuhl \& J. Beckman (Eds.), Action-control: From cognition to behavior (11-39). Heidelberg, Germany: Springer.

2. Ajzen, I., \& Fishbein, M. (1980). Understanding attitudes and predicting social behavior. Englewood Cliffs, NJ: Prentice-Hall. 
3. American Association for the Advancement of Science. (1993). Benchmarks for scientific literacy. New York, NY: Oxford University Press.

4. Artzt, A.F., Armour-Thomas, E., \& Curcio, F.R. (2008). Becoming a reflective mathematics teacher. New York, NY: Lawrence Erlbaum Associates.

5. Bandura, A. (1977). Self-efficacy: Toward a unifying theory of behavioral change. Psychological Review, 84, 191-215.

6. Burns, M. (1998). Math: Facing an American phobia. Sausalito, CA: Math Solutions Publications.

7. Cabrera, A. F., Nora, A., \& Casteneda, M. B. (1993). College persistence: Structural equations modeling tests of an integrated model of student retention. Journal of Higher Education, 64(2), 123127.

8. Edgecomb, M., Britner, S. L., McConnaughay, K., \& Wolffe, R. (2008). Science 101: An integrated, inquiry-oriented science course for education majors. Journal of College Science Teaching, 38(1), 22-27.

9. Enochs, L., \& Riggs, I. (1990). Further development of an elementary science teaching efficacy belief instrument: A preservice elementary scale. School Science and Mathematics, 90, 694-706.

10. Fosnot, C. T., \& Perry, R.S. (2005). Constructivism: A psychological theory of learning. In C. T. Fosnot (Ed.), Constructivism: Theory, perspectives and practice ( $2^{\text {nd }}$ ed., pp. 8-38). New York, NY: Teachers College Press.

11. Hargreaves, A., \& Shirley, D. (2012). The global fourth way. The quest for educational excellence. Thousand Oaks, CA: Corwin.

12. Haury, D. L. (1993). Teaching science through inquiry. ERIC Document Reproduction Service. Columbus, OH: Clearinghouse for Science, Mathematics, and Environmental Education.

13. Heaton, R., \& D. Hartman (2006). A study of middle level students' mathematical understanding using alternative assessments. Paper presented at the MSP Evaluation Summit II, Minneapolis, MN.

14. Hill, H.C., Ball, D.L. \& Schilling, S.G. (2008). Unpacking "Pedagogical Content Knowledge": Conceptualizing and measuring teachers' topic-specific knowledge of students. Journal for Research in Mathematics Education, 39(4), 372-400.

15. Illinois School Report Card. (2017). Retrieved from http://www.illinoisreportcard.com.

16. Illinois State Board of Education. (2009). Retrieved from http://www.isbe.net. 
17. Ingersoll, R.M., \& Strong, M. (2011). The impact of induction and mentoring programs for beginning teachers: A critical review of the research. Review of Educational Research, 81(2), 201 - 233.

18. Jarrett, D. (1997). Inquiry strategies for science and mathematics learning. Portland, OR: Northwest Regional Education Laboratory.

19. Jarrett, D. (1999). Science inquiry for the classroom. Portland, OR: Northwest Regional Educational laboratory.

20. Kiresuk, T.J., Smith, A., Cardillo, J.E. (1994). Goal attainment scaling: Applications, theory, and measurement. Hillsdale, NJ: Lawrence Erlbaum Associates.

21. Lave, J., \& Wenger, E. (1991). Situated learning: Legitimate peripheral participation. New York, NY: Cambridge University Press.

22. Loucks-Horsley, S., Love, N., Stiles, K.E., Mundry S., Hewson, P.W. (2003). Designing professional development for teachers of science and mathematics. Thousand Oaks, CA: Corwin Press, Inc.

23. Michigan Learning Mathematics for Teaching (LMT). (2008). Mathematical knowledge for teaching measures. Ann Arbor, MI: University of Michigan.

24. National Council of Teachers of Mathematics. (2000). Principles and standards for school mathematics. Reston, VA: Author.

25. National Research Council. (1996). National Science Education Standards. Washington, DC: National Academy Press.

26. National Research Council. (2000). Inquiry and the National Science Education Standards: A guide for teaching and learning. Washington, DC: National Academy Press.

27. National Research Council. (2013). Next Generation Science Standards. Washington, DC: National Academy Press.

28. Patton, L., \& K. Schnite. (2005). Implications of teacher priorities for professional development in mathematics and science: Final report. DeKalb, IL: Northern Illinois University.

29. Piburn, M., \& Sawada, D. (2000) Reformed teaching observation protocol (RTOP):Reference manual. ACEPT Technical Report No. INO0-3. Retrieved from http:// www.survey.nagps.org/instruments/RTOP/RTOP_Reference_Manual .pdf.

30. Rutherford, F. J., \& Ahlgren, A. (1990). Science for all Americans. New York, NY: Oxford University Press.

31. Siitonen, J. \& Robinson, H. A. (1998). Empowerment: Links to teachers' professional growth. In Erkkilä, R. Willman, A. \& Syrjälä, L. (1998). Promoting teachers' personal and professional growth. 
Acta Universitas Ouluensis. Scientium Rerum Socialium. Oulu, Finland: Oulu University Press.

32. Taylor, L., \& Fratto, J. M. (2012). Transforming learning through $21^{\text {st }}$ century skills. Boston. MA: Pearson.

33. Tretter, T.R., Moore, B.D., Brown, S. L., Saderholm, J.C., Kemp, A.C., \& Bush, W.S. (2005). Structure and characteristics of physical science assessments designed for middle school teachers. Paper presented at the annual meeting of the Association for the Education of Teachers of Science, Colorado Springs, CO.

34. University of Louisville (2012). Diagnostic science assessments for middle school teachers. Retrieved from http://louisville.edu/education/centers/crmstd/diag-sci-assess-middle.

35. U. S. Department of Education, O. o. t. U., Planning and Evaluation Service (1999). Designing effective professional development: Lessons from the Eisenhower program. Washington, DC: U. S. Department of Education.

36. Wenger, E., McDermott, R., \& Snyder, W.M. (2002). A guide to managing knowledge: Cultivating communities of practice. Boston, MA: Harvard Business School Publishing.

37. Yore, L. D., Anderson, J. O., \& Shymansky, J. A. (2005). Sensing the impact of elementary school science reform: A study of stakeholder perceptions of implementation, constructivist strategies, and schoolhome collaboration. Journal of Science Teacher Education, 16, 6588.

38. Zemelman, S., Daniels, H., \& Hyde, A. (1993). Best practice: New standards for teaching and learning in America's schools. Portsmouth, NH: Heinemann. 